\title{
Research on lateral flow treatment technology to enhance phosphorus removal of AAO process
}

\author{
Shoubin Zhang ${ }^{1, *}$, Yuze $\mathrm{Li}^{1}$, Wenhai Jiao ${ }^{2}$, Liping Qiu${ }^{1}$, Jingxiu Zhong ${ }^{1}$, Wei Sun ${ }^{1}$ \\ ${ }^{1}$ School of Civil Engineering \& Architecture, University of Jinan, NO.336, Nanxinzhuang West Road., Jinan 250022, P.R.China \\ 2 Jinan Municipal Engineering Design \& Research Institute (Group) CO., LTD. Jinan 250101, P.R.China
}

\begin{abstract}
Removing efficiently and recycling of phosphorus in the wastewater, was not only an effective means to prevent and cure the eutrophication of water, but also an important way to realize the recovery of phosphorus resources. In the traditional AAO process, the discharge of phosphorus rich sludge could reach the goal of phosphorus removal. However, the treatment of phosphorus rich sludge was difficult and could not achieve the goal of phosphorus recovery. The lateral flow phosphorus removal treatment technology, building on the side of the traditional AAO system, was an efficient process to realize high efficiency phosphorus removal and phosphorus resources recovery by forming phosphate precipitation or crystallization. In this paper, by summarizing and analyzing the existing technology of lateral flow phosphorus recovery wastewater treatment based on AAO mainstream technology, the future development of this technology was also prospected.
\end{abstract}

\section{Introduction}

Phosphorus, as a non renewable resource, plays an important role in human production and life. However, with the global shortage of phosphorus resources, how to effectively remove and recycle phosphorus resources in wastewater has become a hot research topic at present. On the one hand, the excessive discharge of phosphorus in waste water can lead to eutrophication, threaten the safety of water environment and the safety of drinking water. On the other hand, if the phosphorus in the wastewater can be effectively recovered, it can alleviate the shortage of phosphorus resources to a certain extent. The lateral flow phosphorus recovery wastewater treatment technology has attracted more and more attention in the field of wastewater dephosphorization research and engineering application in recent years due to its advantages of high efficiency phosphorus removal and effective phosphorus recovery. This technology can also improve the mainstream AAO process wastewater treatment while recovering phosphorus. And it's obvious problem to the shortage of raw water carbon source and the contradiction of mud age, the technology has a prominent advantage.

\section{The significance of phosphorus recovery}

Phosphorus is a typical non renewable recycling material in the biosphere, most of which flow in the biosphere and mainly in the form of phosphate ore in nature. It is estimated that the proven phosphate reserves in the world can only be maintained for about 100 years.
According to the statistics of China's Environmental Status Bulletin in 2016, most of the water bodies have listed phosphorus as the main index (Table 1), and the total amount of total phosphorus in the total amount of major pollutants in the sea is increasing year by year. Therefore, the problem of phosphorus recovery in sewage should be concerned on. At present, foreign water treatment technicians have expanded the research field from phosphorus removal to removal and recovery of phosphorus, the study of phosphorus recovery in China with domestic sewage treatment process is still a study at the beginning stage.

Table 1. Waters and its pollution index

\begin{tabular}{|c|c|c|}
\hline $\begin{array}{c}\text { Water } \\
\text { environ } \\
\text { ment } \\
\text { type }\end{array}$ & Waters & $\begin{array}{l}\text { Main pollution } \\
\text { indicator }\end{array}$ \\
\hline \multirow{2}{*}{$\begin{array}{l}\text { Freshw- } \\
\text { ater } \\
\text { enviro- } \\
\text { nment }\end{array}$} & $\begin{array}{c}\text { Seven major river basins } \\
\text { (Yangtze River, Yellow } \\
\text { River, Pearl River, Songhua } \\
\text { River, Huai River, } \\
\text { LiaoRiver) and major rivers }\end{array}$ & $\begin{array}{c}\text { Chemical oxygen } \\
\text { demand, total } \\
\text { phosphorus, five-day } \\
\text { biochemical oxygen } \\
\text { demand }\end{array}$ \\
\hline & $\begin{array}{l}112 \text { important lakes } \\
\text { (reservoirs) including the } \\
\text { Great Lakes (Tai Lake, } \\
\text { Chao Lake, Dianchi) }\end{array}$ & $\begin{array}{c}\text { Total phosphorus, } \\
\text { chemical oxygen } \\
\text { demand, permanganate } \\
\text { index }\end{array}$ \\
\hline $\begin{array}{l}\text { Marine } \\
\text { enviro- } \\
\text { nment }\end{array}$ & $\begin{array}{l}\text { Offshore waters (Bo Sea, } \\
\text { Yellow Sea, East China } \\
\text { Sea, South China Sea) }\end{array}$ & $\begin{array}{l}\text { Inorganic nitrogen and } \\
\text { active phosphate }\end{array}$ \\
\hline
\end{tabular}

\section{Current Status and Limitations of Phosphorus Removal in Traditional AAO Process}

\footnotetext{
* Corresponding author: cea_zhangsb@ujn.edu.cn
} 
The AAO process is one of the most widely used simultaneous nitrogen and phosphorus removal processes in China's sewage treatment plants. The process combines traditional activated sludge process, biological nitrification and denitrification process and biological phosphorus removal process to achieve simultaneous nitrogen and phosphorus removal. The process flow chart is shown in Fig. 1.

In the anaerobic section, the sewage mainly releases a large amount of phosphorus through the action of polyphosphate bacteria, so that the concentration of phosphorus in the sewage is increased. In the anoxic section, the denitrifying bacteria use organic matter for denitrification, and the nitrogen in the reflux liquid is reduced to nitrogen to realize the removal. The purpose of nitrogen. Then the sewage enters the aerobic stage of aeration, the nitrifying bacteria convert ammonia nitrogen into degradable nitrate, denitrification in the anaerobic section, phosphorus absorption by the phosphorus accumulating bacteria, and removal of phosphorus by discharging the phosphorus-rich sludge.

The AAO process is simpler than other simultaneous nitrogen and phosphorus removal processes, with strong impact load resistance, short hydraulic retention time, and does not need to add drugs, as well as operating management costs are low. However, the nitrate content in the return sludge of the aerobic section is too high, which limits the effect of phosphorus release by the phosphorus-concentrating bacteria, which seriously affects the phosphorus absorption efficiency of the aerobic section, and the system sludge age is affected by various The limitation of microorganisms cannot meet the optimal growth conditions of all microorganisms, and it is difficult to further improve the effect of nitrogen and phosphorus removal by the system. In addition, the treatment and disposal method of phosphorus-rich sludge is also a major problem.

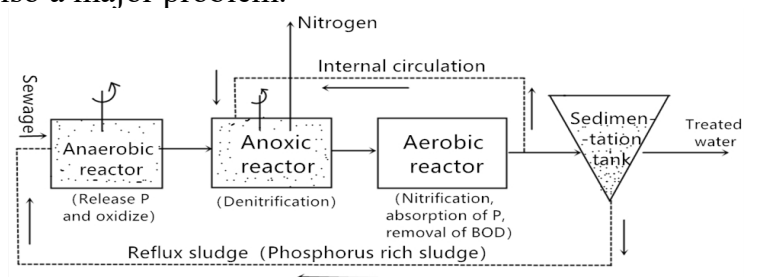

Fig. 1. Flow chart of AAO process

\section{Research Status and Advantages of Lateral Flow Phosphorus Recovery Wastewater Treatment Technology}

Pure phosphorus removal has been difficult to meet the needs of production and life. The effective phosphorus recovery while removing phosphorus is the mainstream trend in the future. In order to recover phosphorus at the same time in the process of phosphorus removal, a lateral flow method is usually adopted. On the basis of the mainstream treatment process, a phosphorus recovery treatment process is added, and the phosphorusrich supernatant liquid after effluent from the anaerobic tank is treated. Phosphorus forms a phosphate product or an inorganic precipitate, which improves the sewage treatment effect of the sewage process while recovering phosphorus, so that the phosphorus removal and the recovery of phosphorus are combined into one. Many scholars at home and abroad have carried out research on the lateral flow phosphorus recovery process.

\subsection{Chemical Precipitation}

The chemical precipitation method is the earliest method of phosphorus recovery. By adding metal salts to the phosphorus-containing wastewater branched from the mainstream process, the phosphate ions in the wastewater are reacted and converted into insoluble phosphate precipitates. Flocculation, solid-liquid separation to remove phosphorus from wastewater to obtain phosphorus-containing sludge. Guo Xiaoma's ${ }^{[1]}$ research on lateral flow chemical dephosphorization of phosphorus-rich wastewater after anaerobic phosphorus release shows that PAC is used as a dosing agent, and the removal rate of $\mathrm{P}$ is increased from $35.5 \%$ to $92.7 \%$ when operating under optimized conditions.

Although the chemical precipitation method is simple in operation and stable in effect, the addition of chemical reagents causes the moisture content of the precipitated sludge to be too high, and further subsequent treatment is required, and the cost is high, so the chemical precipitation method has yet to be developed.

\subsection{Biochemical Method}

\subsubsection{Phostrip Process}

The Phostrip process is composed of a side-by-side dephosphorization tank and a mixed reaction sedimentation tank on the basis of the traditional activated sludge method. The phosphorus is concentrated in the sludge by aerobic excess phosphorus absorption of the phosphorus accumulating bacteria, and then Part of the sludge is in an anaerobic state to fully release the excessively ingested phosphorus, and then adding a chemical agent to precipitate the phosphorus-rich supernatant after anaerobic phosphorus release to achieve the effect of removing phosphorus, and the process flow chart is shown in Fig.2.

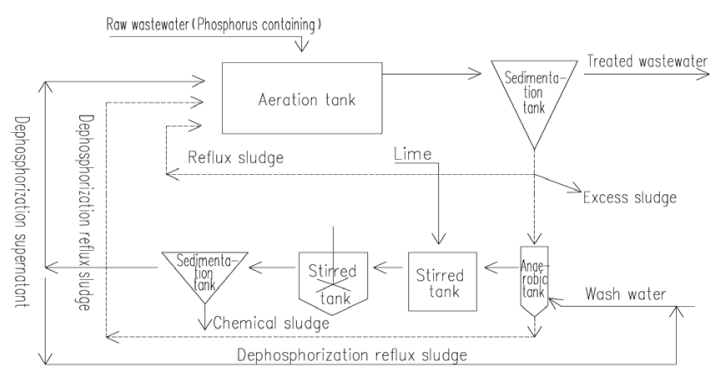

Fig. 2. Flow chart of Phostrip process

Yuan Quan et al ${ }^{[2]}$ combined the Phosrip process with the inverted AAO process to stabilize the effluent $\mathrm{PO}_{4}{ }^{3-}$ below $0.3 \mathrm{mg} / \mathrm{L}$. The Phostrip process combines chemical phosphorus removal with biological phosphorus removal to achieve stable and efficient phosphorus removal It has strong adaptability to water 
quality fluctuations and less mud. However, the process is complicated and difficult to operate and manage.

\subsubsection{Hydrolysis Acidification}

The hydrolysis acidification process has been developed and applied rapidly in Denmark and Sweden ${ }^{[3]}$, but the research and practice of are still lagging behind in our country. This process mainly uses activated sludge to hydrolyze to supplement carbon source and improve the efficiency of denitrification and phosphorus removal. The reflux sludge is partly reacted to the AAO biological pool for reaction, and a few of them enter the hydrolytic acidification reactor for fermentation. After a period of time, the sludge is reflued to the main biological pool to achieve the purpose of strengthening nitrogen and phosphorus removal. The specific process chart is shown in Figure3. Wang Jianlong ${ }^{[4]}$ etc. combined the traditional AAO reactor with the hydrolytic acidification reactor. Under appropriate reaction conditions, the removal rate of $\mathrm{P}$ can reach $87 \%$ and the sludge reduction rate is $56.5 \%$, which effectively improves the biodegradability of sewage. However, the hydrolytic acidification process is sensitive to toxic substances, and has certain requirements for influent wastewater. Improper operation may lead to failure of reactor operation.

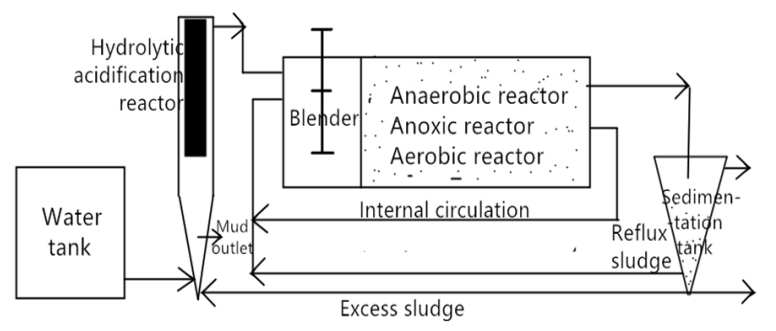

Fig.3. Flow chart of hydrolysis acidification process

\subsection{Crystallization}

Phosphorus recovery by crystallization is currently considered to be the most cost-effective phosphorus recovery technology. Based on the original mainstream treatment process of AAO, a lateral flow crystallization reactor can be added. On the basis of efficiency, the recovery of phosphorus resources is maximized, which has improved the limitations of traditional phosphorus removal technologies to some extent. At present, phosphorus in crystallization recovery wastewater mainly includes Magnesium ammonium phosphate (MAP) crystallization method and Hydroxyapatite (HAP) crystallization method. MAP is suitable for high concentration phosphorus-containing wastewater, and HAP is more suitable for medium and low concentration.

\subsubsection{MAP Crystallization}

MAP, ie struvite $\left(\mathrm{MgNH}_{4} \mathrm{PO}_{4} \cdot 6 \mathrm{H}_{2} \mathrm{O}\right)$, after the sewage is denitrified and dephosphorized by the mainstream process, the phosphorus-rich supernatant in the anaerobic tank is split into the bypass MAP crystallizer, and ammonia nitrogen and magnesium salts are added.
The MAP crystal can be obtained by controlling the appropriate operating conditions. The nitrogen source is generally $\mathrm{NH}_{4} \mathrm{Cl}$ and $\left(\mathrm{NH}_{4}\right)_{2} \mathrm{SO}_{4}$, etc., and the magnesium source is $\mathrm{MgCl}_{2}$ or $\mathrm{Mg}(\mathrm{OH})_{2}$.

In order to improve the recovery rate of phosphorus in sewage, domestic and foreign scholars have researched and developed various types of crystallization reactors. Some researchers ${ }^{[5]}$ designed and studied the internal circulation of the MAP reactor. The reactor was set up to the reaction zone and the crystallization area, and the two regions had internal circulation circuits. Under the optimal operating conditions, the recovery rate of phosphorus reached $78 \%$. Battistoni et al ${ }^{[6]}$ compared the effect of crystallization of phosphorus in a fluidized bed on a scale and a half scale. It was found that $80 \%$ phosphorus was recovered from the supernatant by inducing MAP crystallization with quartz sand as a seed crystal in a fluidized bed crystallization reactor. RAHMAN M M et al ${ }^{[7]}$ designed a simple continuous feed plexiglass reactor to treat pig manure wastewater with a volume of $12.3 \mathrm{~L}$. The wastewater was added to the wastewater and $\mathrm{MgCl}_{2}$ feedstock, and the phosphorus recovery rate reached $93 \%$. GUADIE A et al $\mathrm{a}^{[8]}$ compared the new fluidized bed reactor with vertebral body and vertebral body. It was found that the fluidized bed reactor with vertebral body greatly improved the recovery rate of phosphorus. Under the optimal conditions obtained by experiments. The recovery rate of phosphorus in low-quality phosphorus wastewater $(\rho(P) 12.5 \mathrm{mg} / \mathrm{L})$ reached $93 \%$, and the recovery rate of phosphorus in high-quality phosphorus wastewater $(\rho(P)$ $120 \mathrm{mg} / \mathrm{L}$ ) was $98 \%$.

\subsubsection{HAP Crystallization}

HAP, that is, calcium hydroxyphosphate $\left(\mathrm{Ca}_{5}\left(\mathrm{PO}_{4}\right)_{3} \mathrm{OH}\right)$, is a method in which crystals of calcium hydroxyphosphate are formed by seeding, and there is an advantage that the product is easily separated and the crystallization rate is fast.

The main influencing factors of HAP crystallization are $\mathrm{pH}$, the ratio of $\mathrm{Ca}$ to substance $\mathrm{P}$, and seed crystals. Shi Lei ${ }^{[9]}$ found that the phosphorus removal efficiency increased first and then decreased with the increase of $\mathrm{pH}$. When the $\mathrm{pH}$ reached 8.5 , it was close to the maximum value. When $\mathrm{pH}>9$, the effect of phosphorus removal will be affected. Zou Haiming ${ }^{[10]}$ and other studies have found that increasing the ratio of $\mathrm{Ca}$ to $\mathrm{P}$, the effect on phosphorus recovery rate increases rapidly and then stabilizes. When the ratio of $\mathrm{Ca}$ to $\mathrm{P}$ is less than 1.5 , the phosphorus recovery rate is lower; when $\mathrm{Ca}$ When the ratio of the amount of substance $\mathrm{P}$ to $>2.5$, the phosphorus recovery rate is $>92 \%$, but the ratio of $\mathrm{Ca}$ to substance $\mathrm{P}$ continues to increase, and the phosphorus recovery rate does not increase much.

The choice of seed crystals is currently a hot topic in the research of HAP crystallization, which has led to the research and development of many scholars and the development of various seed crystals. Kim et $\mathrm{al}^{[11]}$ found that the effect of phosphorus slag as a seed slag for phosphorus removal was better than that of quartz sand, 
bone charcoal and apatite during the crystallization reaction. BELLIER.N et $\mathrm{al}^{[12]}$ studied the phosphorus removal effects of four apatites found in North America, and found that sedimentary rocks have better effects than igneous rocks, probably due to the higher density of sedimentary rocks. The reactants for recovering phosphorus by HAP crystallization are almost free of sludge, and the purity is high, but the reaction conditions are high.

\section{Conclusion}

In summary, in view of the limitations of the traditional AAO process for nitrogen and phosphorus removal, the use of increased lateral flow treatment of wastewater not only improves the efficiency of phosphorus removal, but also achieves the recovery and utilization of phosphorus to a certain extent, for environmental benefits and the shortage of phosphorus resources has contributed a certain amount. Compared with the above-mentioned bypass phosphorus recovery process, it is found that the amount of sludge generated in the crystallization wastewater treatment process is much smaller than that of the biological method and the chemical precipitation method, and the crystal purity of the precipitated crystal is high, and the nitrogen and phosphorus in the sewage can be recovered efficiently. The method is invested in the province, the effluent water quality is good, and the temperature is less affected. At the same time, the crystal product can be used as fertilizer, feed additive, coating and raw material for producing phosphate rock, which can generate certain economic benefits, and is a kind of ecological benefit and society. When applied to phosphorus recovery in wastewater treatment plants, sludge treatment and wastewater plant operating costs can be reduced.

\section{Outlook}

The AAO process is the mainstream process commonly used in wastewater treatment plants at this stage, but it is limited in improving the phosphorus removal effect. By adopting the lateral flow phosphorus recovery process, on the basis of not affecting the AAO mainstream process to remove other pollutants, the sewage treatment process can not only improve the efficiency of phosphorus removal from sewage, but also solve the problem of shortage of some phosphorus resources and reduce the environmental hazard of phosphorus sludge discharge .

However, at present, the development of lateral flow reactors in China still have problem, the application process is complicated, the control operation system is not formed, and the operation management and addition of chemical agents make the cost higher, which also limits the process to a certain extent.And the role of the lateral flow phosphorus recovery process and the synergistic treatment of mainstream bio-units, the impact on the removal of other pollutants, and the form of phosphorus recovery products require further research and development.

\section{Acknowledgements}

This work was financially supported by the Shandong Provincial Key Research and Development Program(2016CYJS07A03-2), and partly supported by Shandong Provincial Key Research and Development Program(2017GSF17105).

\section{References}

1. Guo Xiaoma modified A 2O- side stream phosphorus removal process nitrogen and phosphorus removal and characteristics of microbial colonies [D]. Ocean University of China, 2015.

2. Yuan Quan, Du alliance, Chen Junjie. Application of side stream phosphorus removal process in municipal wastewater treatment plant [J]. environmental engineering, 2005, 23 (6): 28-29.

3. Vollertsen J, Petersen G, Borregaard V R. Hydrolysis and fermentation of activated.

4. Wang Jianlong, Peng Yongzhen, Liu Ying, et al. Simultaneous nitrogen and phosphorus removal and sludge reduction in hydrolytic acidification /AAO process [J]. China water supply and drainage, 2007, 23 (23): 1-5.

5. LIU Z G, ZHAO Q L. Enhancing phosphorus recovery by a new, 2008, 99 (14):

6. Battistoni P, Pavan P, Cechi F. Struvite crystallization:a feasible and reliable way, 2000, 34 (11):

7. RAHMAN M M, LIU Y H. Recovery of struvite from animal wastewater.

8. GUADIE A, XIA S Q. Enhanced struvite recovery from wastewater using a, 2014, 26 (4):

9. Shi Lei. Characteristics of phosphorus removal and phosphorus recovery from hydrated calcium silicate [D]. Chongqing: Chongqing University, 2012:35-39.

10. Zou Haiming, Lv Xiwu, Li Ting. Analysis of main factors affecting phosphorus recovery from HAP crystallization wastewater [J]. Journal of Southeast University, 2013, 43 (5): 1005-1010.

11. Kim E H, Yim S B, Jung H C.Hydroxyapatite crystallization from a.

12. Bellier N, Chazarenc F, Comeau Y. Phosphorus removal from wastewater by, from 2006, 40 (15):2965-71. 